\title{
Identifying the effects of oceanographic features and zooplankton on prespawning herring abundance using generalized additive models
}

\author{
Christos D. Maravelias ${ }^{1,2, *}$, David G. Reid ${ }^{2}$ \\ ${ }^{1}$ Department of Zoology, University of Aberdeen, Tillydrone Avenue, Aberdeen AB24 3TZ, Scotland, UK \\ ${ }^{2}$ Scottish Ofíice of Agriculture Environment and Fisheries Department (SOAEFD), Marine Laboratory, PO Box 101, \\ Victoria Road, Aberdeen AB11 9DB, Scotland, UK
}

\begin{abstract}
Spatial distribution patterns of prespawning herring were analyzed in relation to zooplankton biomass, sea-surface temperature and salinity, temperature and depth of the thermocline (fronts) and the temperature difference between surface and bottom water. Data were collected in midsummer 1995 during the ICES coordinated herring acoustic survey of the ICES Division IVa. We used generalized additive models (GAMs), nonparametric generalization of multiple linear regression, to test the hypothesis that prespawning herring distribution is related to zooplankton availability and the oceanography around the Shetland Islands (UK), with particular reference to inflows from the Slope Current. The results of this study supported this hypothesis. We found that zooplankton biomass and the location of ocean fronts influence the dustribution of prespawning herring. Mean herring abundance was consistently highest in areas having a surface salinity of $35.1 \mathrm{ppt}$ and where the zooplankton abundances were higher. Results indicated that herring appeared to prefer the well-mixed waters and transition zones and avoided the stratified and frontal areas. The present results also suggested that prespawning aggregations of herring followed the movements of zooplankton to deeper and cooler waters beneath the thermocline during summer. Waters with specific salinity and temperature properties are attractive to herring due to the process of frontal mixing which enhances primary and secondary production. These waters are ultimately linked with the Slope Current which is responsible for the advection of warm, nutrient-rich, saline water into the North Sea ecosystem.
\end{abstract}

KEY WORDS; Herring - Oceanography - Zooplankton - North Sea - Generalized additive models

\section{INTRODUCTION}

Physical events such as the alternation of vertical mixing and stratification, lead to enhanced production, mainly by diatoms. Cushing (1989) showed that diatoms are the basis of the traditional food chain by which energy and materials are passed through mesozooplankton (such as copepods) to fish. It is known that regions having a high hydrographic activity are utilized as feeding areas by migrant adults (Longhurst 1984). The 'frontal effect' usually becomes apparent in the accumulation of biomass (Raid 1989). Although

\footnotetext{
- Correspondence address: Scottish Office of Agriculture Environment and Fisheries Department (SOAEFD), Marine Laboratory, PO Box 101, Victoria Road, Aberdeen AB11 9DB, Scotland, UK. E-mail: maraveliasc@marlab.ac.uk
}

primary and secondary productivity have been found to be higher in frontal areas, peak abundances of herring larvae have been observed in transitional water in conjunction with peak copepod production (Kiørboe et al. 1988). Shoals of herring have been noted to be more abundant in the boundary areas between different water masses (Raid 1989). Conversely, the absence of strong vertical mixing events is associated with relatively low fish productivity (Mann 1993).

A number of studies have shown that pelagic fish distributions are influenced by environmental factors (Sutcliffe et al. 1977, Raid 1989, Mann 1993 and references therein). In the case of the North Sea herring, significant relationships between herring distribution and sea-surface temperature and salinity have been found (Maravelias 1993). It was suggested that the relationship between herring distribution and salinity 
and temperature was likely to be indirect. The herring appeared to be densest near boundary areas between mixed and stratified water. Such areas are characterised by relatively higher productivity of zooplankton which herring utilise as food (Raid 1989). The Shetland (UK) area of the North Sea is a hydrographically dynamic area. The main feature is the Slope Current, which is responsible for the input of warm, saline, nutrient-rich water west of the Shetland-Orkney Islands. Some of this water enters the North Sea via the East Shetland Atlantic inflow (flowing north and then east of the Shetland Islands) and the Fair Isle Current (flowing between Shetland and Orkney) (Reid et al. 1997). The remainder of the water enters the North Sea via the Norwegian Trench.

If fish stocks are more or less adapted to particular environmental conditions, a change in either direction is likely to be detrimental (Shepherd et al. 1984). The response to environmental factors is therefore unlikely to be monotonic, linear or parametric. As a result, routine methods of statistical analysis, (namely linear regression models, multiple or not) are inadequate to detect and successfully quantify any environmental effect. A Generalized Additive Model (GAM) is a nonparametric regression technique offering advantages over conventional regression techniques because it is not tied to a particular functional relationship (i.e. linearity) and because it is less restrictive in assumptions about the underlying statistical distribution of the data. In GAMs, the covariates are assumed to affect the dependent variable, in this case fish abundance, through additive, unspecified (not linear, not parametric) smooth functions.

In the present paper, we further examined the hypothesis that herring distribution is related to the presence of boundary zones and zooplankton distribution by studying these relationships both east and west of the Shetland Islands. The west is dominated by the effects of the Slope Current, and the east is mainly North Sea water with inflows of Atlantic water around the islands.

Our study was designed to establish quantitative relationships between the spatial distribution of prespawning herring Clupea harengus, L. abundance and biotic and environmental factors over a wide geographical area, i.e. the northern North Sea, using acoustic backscatter data for information about fish distribution and oceanographic data for the environmental factors. Fisheries acoustic methods allow a quasi-synoptic, mesoscale view of the spatial structure of the population to be obtained. The term 'quasisynoptic' is adopted as an acoustic survey takes a finite time, in this case about 3 wk. The herring are known to be migrating during this period; however, migration speeds derived from tag recoveries indicate rates of movement of less than 1 nautical mile ( $n$ mile) per day
(Simmonds 1995), while the survey time between adjacent transects (15 $\mathrm{n}$ miles spacing) is approximately $24 \mathrm{~h}$. Therefore it is reasonable to conclude that the surveys are good indicators of the spatial structure of the population and that migration, while present, is a minor problem.

The simultaneous collection of a wide range of ancillary variables, i.e. biotic (e.g. zooplankton) and hydrographic (e.g. depth-temperature profiles, salinity), during an acoustic survey enables an understanding of the relationship between population distribution and environment. Herring abundance distribution is quantitatively related for the first time to biotic and abiotic factors over such a wide area using regression without the restrictive linearity assumption (GAM). Herring abundance was derived from the 1995 ICES coordinated acoustic survey of in the North Sea (ICES Division IVa). Oceanographic parameters examined included seasurface salinity and temperature, temperature at $60 \mathrm{~m}$, thermocline depth and differences between surface and bottom temperature values as indicators of mixing/stratification and presence of currents and frontal areas. Zooplankton abundances were assessed using plankton net samples taken during the survey.

\section{MATERIALS AND METHODS}

Acoustic survey. The survey was carried out on prespawning concentrations of autumn-spawning herring from 8 to 27 July 1995 using the Fisheries Research Vessel 'Scotia' (Fig. 1). The acoustic survey was carried out using a Simrad EK500 $38 \mathrm{kHz}$ sounder and echo integrator. Further data analysis was carried out using Simrad BI500 and Marine Lab Analysis systems. The survey track was selected to cover the area based on the limits of herring densities found in the previous years. A transect spacing of $15 \mathrm{n}$ miles was used. The ends of the tracks were positioned at $1 / 2$ the actual track spacing from the area boundary, giving equal track length in any rectangle within the area. The betweentrack data could then be included in the data analysis. The origin of the survey grid was selected randomly and the grid was laid out with systematic spacing from the random origin. Trawl hauls were carried out during the survey on the denser echo traces. The trawl hauls were used to partition school echo integrals between species, based on trawl composition. The bulk of the hauls was predominantly herring. Each haul was sampled for length, age, maturity and weight of individual herring. Data from the echo integrator were summed over quarter hour periods $(2.5 \mathrm{n}$ miles at 10 knots). Echo integrator data were collected from $9 \mathrm{~m}$ below the surface (transducer at $5 \mathrm{~m}$ depth) to $1 \mathrm{~m}$ above the seabed (details of equipment and survey design are 


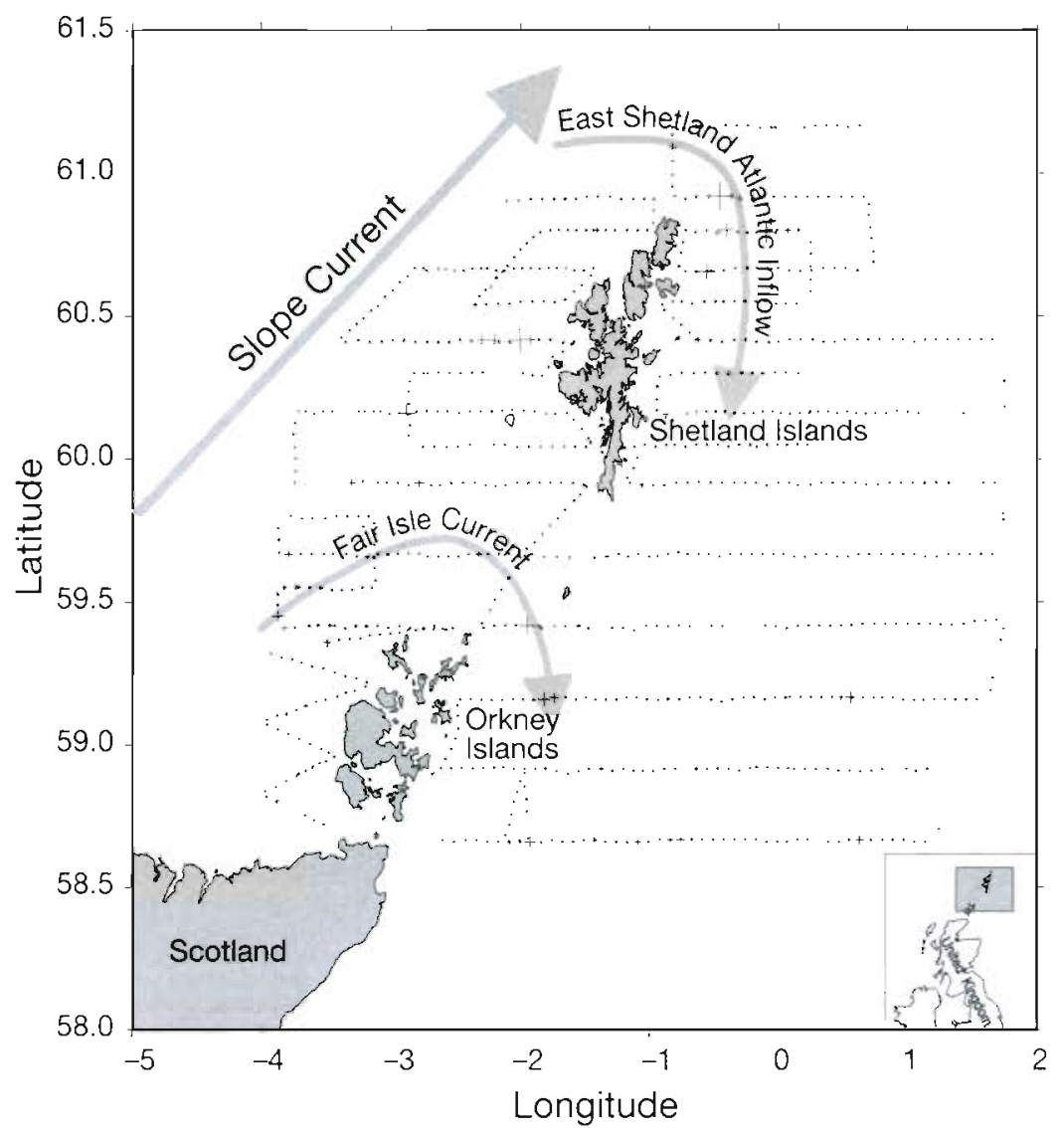

Fig. 1 Survey track of the Fisheries Research Vessel 'Scotia' during the northern North Sea herring acoustic survey in July 1995. Symbols are proportional to herring biomass

reported in Simmonds et al. 1996). Herring were found mostly in water with the seabed deeper than $100 \mathrm{~m}$, with traces being found in waters with depths of up to $250 \mathrm{~m}$. The herring density data were available on a fine scale along the survey track (every $2.5 \mathrm{n}$ miles) in the form of a herring echo abundance index (EAI). The herring EAI is calculated by partitioning the echo integral from the echo integrator and is linearly related to herring biomass (Foote 1983).

Plankton samples were taken vertically using a standard plankton net ( $250 \mu \mathrm{m}$ mesh) from the first $60 \mathrm{~m}$ of the water column. Samples were fixed and preserved in excess borax buffered $4 \%$ formaldehyde solution. Species were identified, counted and converted to dry weights. In addition, numerical densities of copepod developmental stages were converted to dry weight using a standard set of stage length and dry weight data, in turn derived from a wide range of sources including unpublished data and a variety of literature sources (Hay 1995). These were then converted to biomass $\mathrm{m}^{-3}\left(\mathrm{mg} \mathrm{m}^{-3}\right)$ for the top $60 \mathrm{~m}$ of the water column. For the purposes of the present study, only the small crustacean category was used. This category was dominated (99\%) by calanoid copepods at various stages of development. Calanus is believed to be the main prey of herring (Parrish \& Saville 1965).

Sea-surface temperature and salinity were collected simultaneously using a thermosalinograph (Ocean Data Model: TSG103) connected to the vessel's nontoxic sea water supply. Additionally, 108 CTD (SeaBird CTD19) and XBT (Expendable Bathythermograph: an instrument launched from the ship which measures temperature changes with depth, but is not retrieved; Spartan systems) stations were carried out during the survey. At 8 stations, the CTD and XBT cast were carried out simultaneously for cross-calibration purposes. Salinity samples were taken for calibration and analysed using a Guildline Portasal salinometer back in the laboratory.

Data analysis. Sea-surface salinity and sea-surface temperature were derived from the thermosalinograph. Temperature at $60 \mathrm{~m}$, temperature difference between surface and seabed (surface-bottom temperature) and depth of the thermocline were derived from the 108 CTD and XBT stations. Thermocline depth was taken as the depth at which temperature had dropped to $90 \%$ of the difference between surface and $60 \mathrm{~m}$ temperatures. On most casts the thermocline occurred at depths less than $60 \mathrm{~m}$. This definition of the thermocline is consistent with the hydrography of the study area (W. Turrell pers. comm.) and has been used in similar studies (Swartzmann et al. 1995). We used the local regression model, LOESS, to model temperature at $60 \mathrm{~m}$, thermocline depth and bottom temperature as a function of depth, latitude and longitude and then used LOESS in a predictive mode to interpolate onto the herring EAI locations. For zooplankton biomass, kriging, which explicitly accounted for the presence of spatial autocorrelation, was used instead. Scatter plots of the all the studied variables were produced, in order to visualize and suggest possible relationships between the variables.

We used GAMs (Hastie \& Tibshirani 1990, Swartzman et al. 1992) to investigate the relationships suggested by the scatter plots. A GAM is a non-parametric regression method with less strict assumptions of normality and linearity than linear regression. The standard linearity assumption is extended to include any underlying probability distribution from the exponential family (including the Poisson, gamma, normal and 
binomial distributions). We used the normal distribution The dependent variable, here herring abundance, is modelled as the additive sum of unspecified non-parametric functions of hypothesized covariates and their interactions. The least squares estimate of the multiple linear regression is replaced by a local smoother. In the present study we used a cubic spline smoother, s (Hamming 1973). A backfitting algorithm (Hastie \& Tibshirani 1990) cycles through the covariates, improving the overall smoothness at each iteration until a threshold level of the deviance (the measure used for fit of the model to the data) is achieved. All available variables and their first order interactions were initially included in the model. Backward stepwise elimination was used to select a set of significant covariates. Approximate $F$-tests were used to compare models (Hastie \& Tibshirani 1990). The final GAM for the eastern area was: herring abundance = $s$ (zooplankton) + s(salinity) $+s$ (surface - bottom temperature $)+s$ (temperature at $60 \mathrm{~m})+s$ (zooplankton $x$ temperature $)+s($ zooplankton $x$ thermocline depth); and for the western area: herring abundance $=s$ (zooplankton $)+s$ (salinity $)+s($ surface - bottom temperature $)+$ $s$ (zooplankton $x$ temperature $)+s($ zooplankton $x$ temperature at $60 \mathrm{~m}$ ). Permutation tests and bootstrap resampling (700 samples) gave the significance levels and confidence intervals for the above models and covariates (the techniques are described in detail in Swartzman et al. 1992).

\section{RESULTS}

The scatter plots (Figs, $2 \& 3$ for the east and west parts of the survey respectively) suggest the following relationships:

East. (1) Areas of high zooplankton abundance ( $>50 \mathrm{mg} \mathrm{m}^{-3}$ ) were also the areas of highest herring abundance.

(2) Herring were abundant in areas of high surface salinity (>34.5 ppt), with the largest aggregations found in waters with surface salinity greater than $35 \mathrm{ppt}$.

(3) Temperatures at $60 \mathrm{~m}$ depth between 9 and $10^{\circ} \mathrm{C}$ were associated with high herring abundance. Herring was also present when the temperature at $60 \mathrm{~m}$ was around $7^{\circ} \mathrm{C}$.

(4) Large herring aggregations tended to occur at surface temperatures between 11 and $12.5^{\circ} \mathrm{C}$ and to a lesser extent around $14^{\circ} \mathrm{C}$.

(5) A deep ( $>35 \mathrm{~m}$ ) thermocline was associated with high herring biomass, although there was some evidence of high herring biomass with a shallow thermocline $(<20 \mathrm{~m})$.

(6) Herring biomass was found to be higher in well-mixed waters (smallest surface-bottom temperature values) and lower in stratified waters (largest surface - bottom temperature values).

West. (1) Herring were present even when the zooplankton biomass was low, however, the highest herring abundances were associated with the highest zooplankton abundances.

(2) Herring were abundant in areas of high surface salinity ( $>34.8 \mathrm{ppt}$ ), with the largest aggregations found in waters with surface salinity greater than $35 \mathrm{ppt}$.

(3) Although the temperatures at $60 \mathrm{~m}$ depth were warmer compared with the east part of the survey, herring biomass was the highest for temperatures around $10^{\circ} \mathrm{C}$.

(4) Large herring aggregations tended to occur at surface temperatures between 11.5 and $12.5^{\circ} \mathrm{C}$.

(5) Large herring abundances occurred over a range of thermocline depths (20 to $50 \mathrm{~m}$ ).

(6) Areas dominated by fronts and currents (i.e. surface-bottom temperature values close to zero) were characterised by low herring abundance; well-mixed waters and transition zones (i.e. intermediate surface - bottom temperature values) were associated with the highest herring abundances.
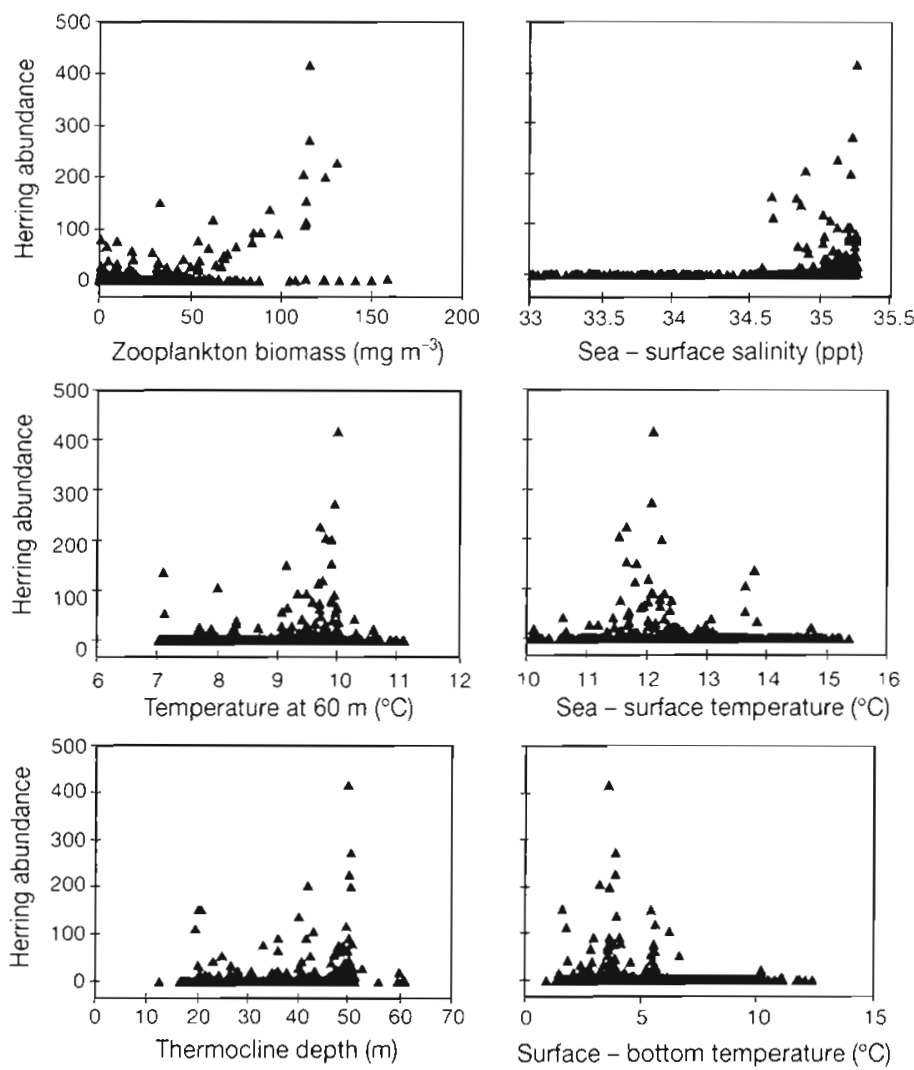

Fig. 2. Scatterplots showing the relationship between herring biomass and zooplankton biomass, surface salinity, temperature at $60 \mathrm{~m}$, surface temperature, thermocline depth and surface - bottom temperature for the area east of the Shetland-Orkney Islands, July 1995 

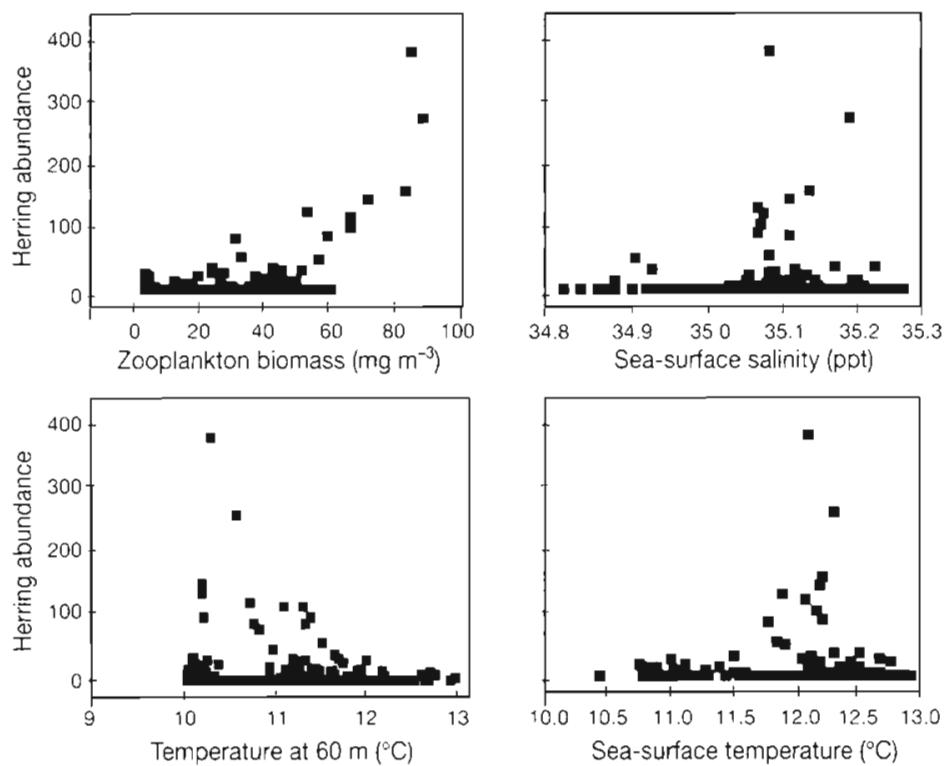

Sea-surface temperature $\left({ }^{\circ} \mathrm{C}\right)$
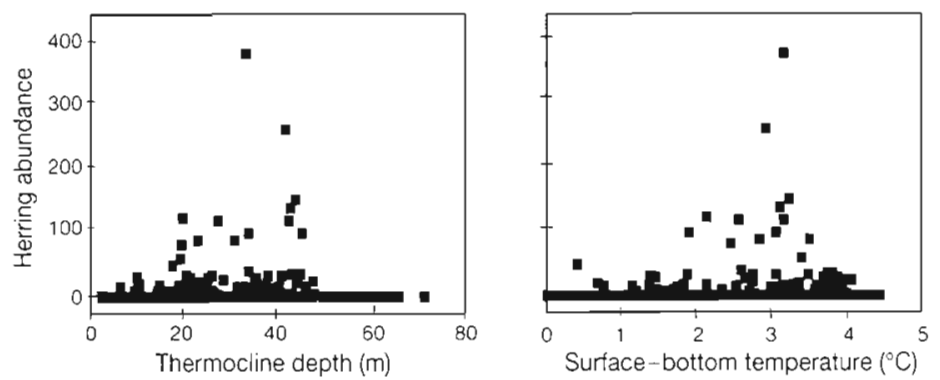

Fig. 3. Scatterplots showing the relationship between between herring biomass and zooplankton biomass, surface salinity, temperature at $60 \mathrm{~m}$, surface temperature, thermocline depth and surface-bottom temperature for the area west of the Shetland-Orkney Islands, July 1995

At first, all the covariates entered the model, and then backward stepwise elimination was used to select a set of significant covariates. Total herring abundance (from the acoustic record) was finally regressed for (1) the area east of the Shetland-Orkney Islands, against zooplankton abundance, surface salinity, temperature at $60 \mathrm{~m}$, and surface-bottom temperature values. Zooplankton abundance/thermocline depth and zooplankton abundance/surface temperature interactions were also included as covariates; and (2) the area west of the Shetland-Orkney Islands, against zooplankton abundance, surface salinity and surface-bottom temperature values. Zooplankton abundance/temperature at $60 \mathrm{~m}$, and zooplankton abundance/surface temperature interactions were also included as covariates. A further approach was undertaken in order to determine if the observed relationships were due to the presence of a small number of high fish values. The 5 highest herring abundance values were removed and the data were re-analyzed.
However, there was no significant change either in the shape of the relationships (i.e. GAM plots) or in the significance values of the models (not shown)

In both areas, all explanatory variables were significant at the 0.05 significance level. Zooplankton abundance was the most significant explanatory variable for both areas, along with its interactions with water temperature at 60 $m$, thermocline depth and surface temperature. The effects that the explanatory variables have on herring abundance can be shown by examining the fitted contribution of each variable to total abundance plotted against the value of the variable.

Abundance was greatest around the Shetland-Orkney Islands. As Figs. 4 \& 5 illustrate, salinity, zooplankton and surface-bottom temperature had somewhat similar effects on herring abundance in the 2 areas. Herring abundances were, on average, greatest at a surface salinity of about $35.1 \mathrm{ppt}$ and average abundance was high at a surface-bottom temperature value of around $2^{\circ} \mathrm{C}$.

For the east part of the survey, herring abundance increased with increasing zooplankton abundance, whereas for the west, the average herring abundance was greater for zooplankton values above a threshold $>60 \mathrm{mg} \mathrm{m}^{-3}$. The interpretation of the figures, above $80 \mathrm{mg}$ $\mathrm{m}^{-3}$ (for west) and $100 \mathrm{mg} \mathrm{m}^{-3}$ (for east) should be treated with caution. The density of points for different covariate values is shown by the rug under the single covariate effects plots (Figs. 4 \& 5). Fewer points lead to larger standard error bands. Thus the apparent high herring abundance for the higher zooplankton abundances (values $>80 \mathrm{mg} \mathrm{m}^{-3}$ for the west and $>100 \mathrm{mg} \mathrm{m}^{-3}$ for the east) are derived from a few observations only. One clear difference between the 2 areas is that while for the east the herring abundance was high at $60 \mathrm{~m}$

Table 1. Significance values (p-levels) for 1995 ICES herring summer acoustic survey GAM covariates for the east and west part of the survey. Level of significance was set to 0.05 . ns: non-significant

\begin{tabular}{|llc|}
\hline Covariate & East & West \\
\hline Zooplankton abundance & 0.0 & 0.0 \\
Surface salinity & 0.01 & 0.0001 \\
Temperature $60 \mathrm{~m}$ & 0.02 & $\mathrm{~ns}$ \\
Surface - bottom temperature & 0.0003 & 0.007 \\
Zooplankton-thermocline depth interaction & 0.0 & $\mathrm{~ns}$ \\
Zooplankton-surface temperature interaction & 0.0 & 0.0 \\
Zooplankton-temperature at 60 m interaction & $\mathrm{ns}$ & 0.0 \\
\hline
\end{tabular}



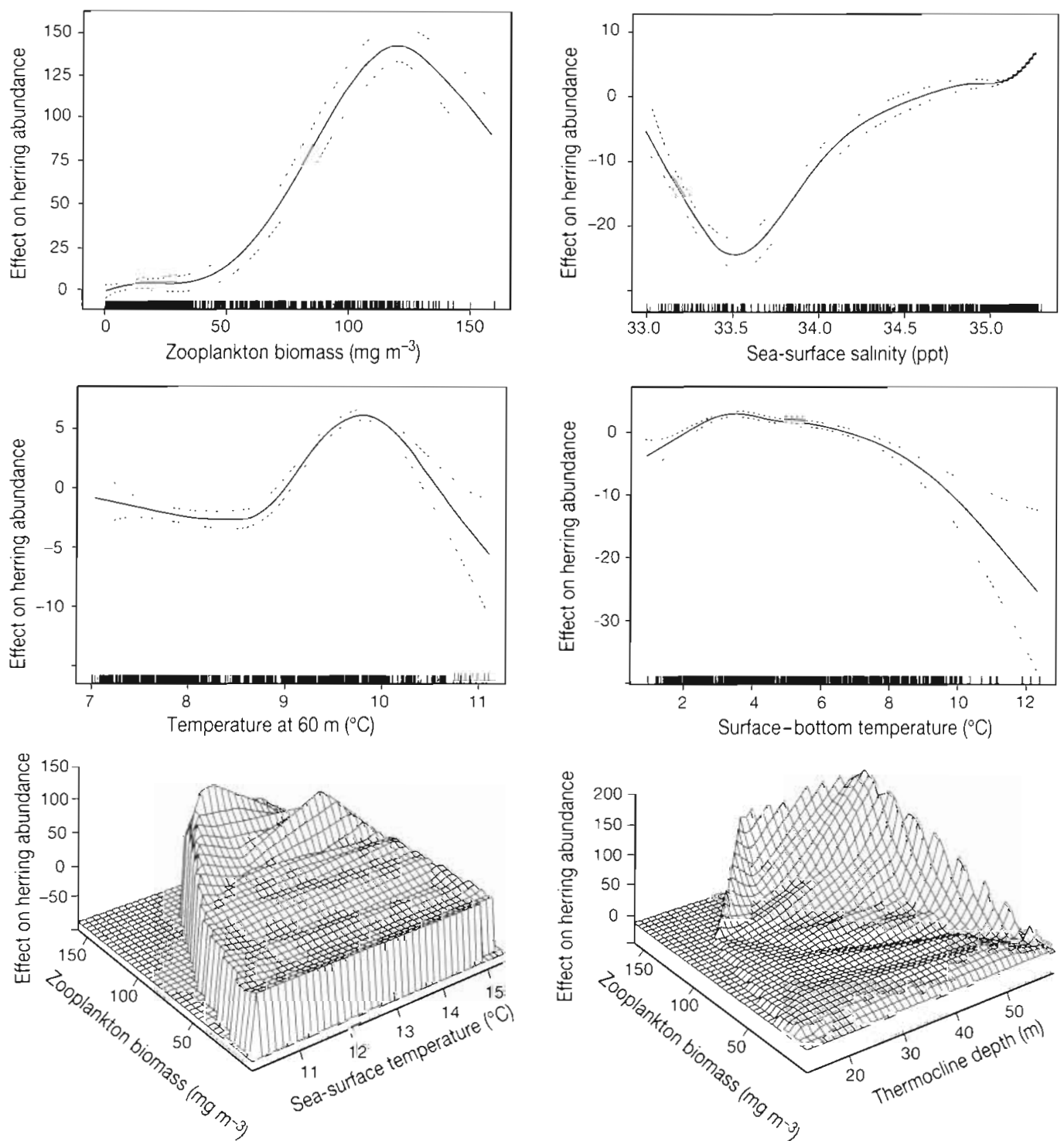

Fig. 4. GAM-derived effects of zooplankton, salinity, temperature at $60 \mathrm{~m}$, difference between surface and bottom values of temperature, surface temperature and thermocline depth for the area east of the Shetland-Orkney Islands in summer 1995. Zooplankton, salinity, temperature at $60 \mathrm{~m}$ and surface-bottom temperature effects, are shown with 2 SE ranges around the estimated effects

at temperatures between 9 and $10.5^{\circ} \mathrm{C}$, the temperature at $60 \mathrm{~m}$ covariate did not have any significant main effect on herring abundance in the west area.

As Table 1 shows there were significant interactions of herring abundance with zooplankton abundancesurface temperature interaction for both areas. In the east, for temperatures between 11 and $12.5^{\circ} \mathrm{C}$, there was an increase in average herring abundance with increasing high zooplankton abundances. For a given zooplankton abundance (of around $100 \mathrm{mg} \mathrm{m}^{-3}$ ) there was an increase in the herring abundance with increasing surface temperature up to $14^{\circ} \mathrm{C}$. There was no clear relationship between herring and surface tem- perature for low zooplankton abundance. In the west, for areas with high zooplankton abundance, there was an increase in average herring abundance with increasing surface water temperature. As for east, there was no obvious relationship for the low zooplankton abundances. Therefore, for the entire survey area (east and west) for surface temperatures around $12^{\circ} \mathrm{C}$, average herring abundance increased with increasing zooplankton abundance.

The zooplankton-temperature at $60 \mathrm{~m}$ interaction, which was highly significant for the west. was not significant for the east. Higher herring abundance was associated with high zooplankton abundances and a 

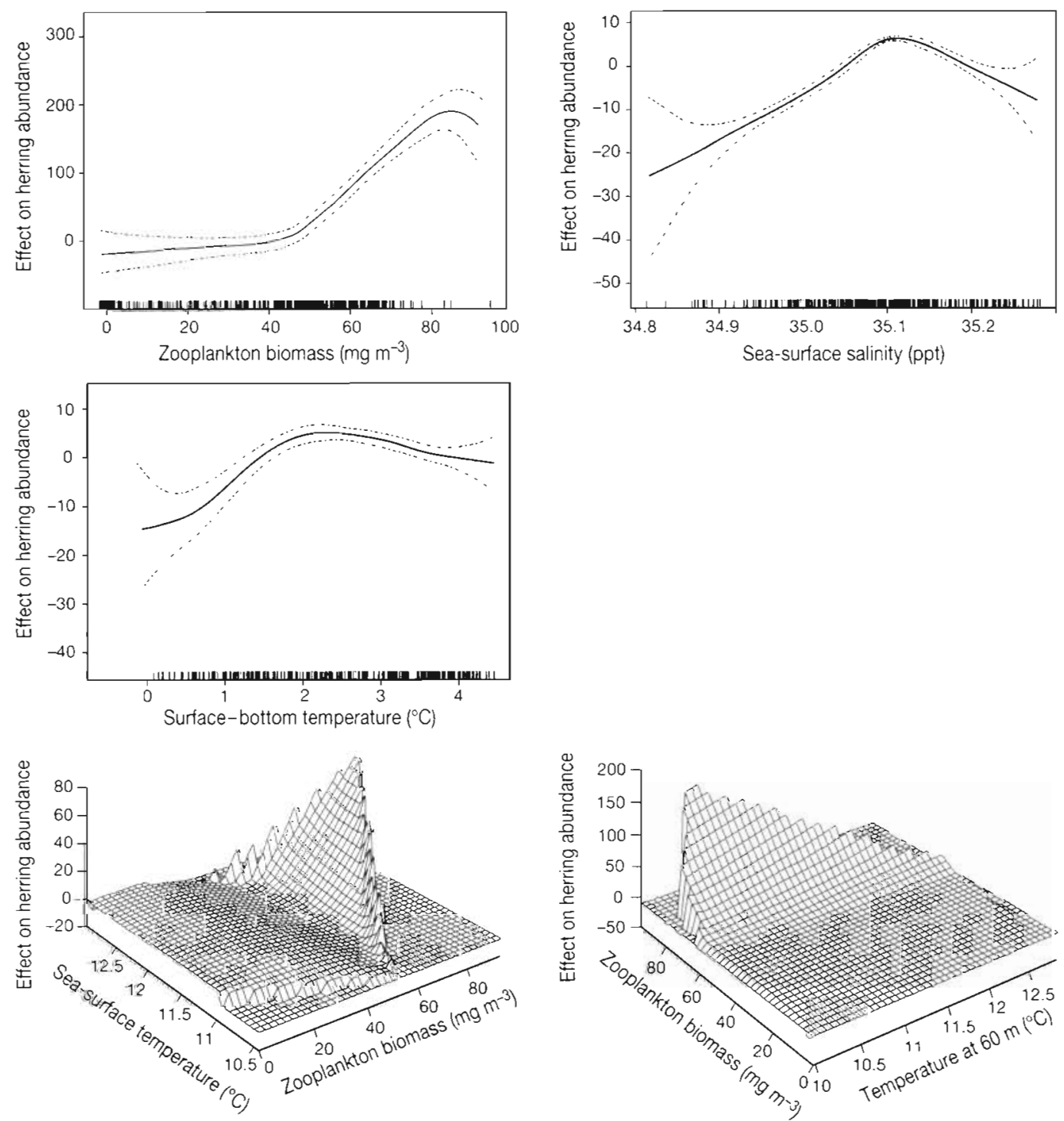

Fig. 5. GAM-derived effects of zooplankton, salinity, difference between surface and bottom values of temperature, surface temperature and temperature at $60 \mathrm{~m}$ for the area west of the Shetland-Orkney Islands in summer 1995. Zooplankton, salinity and surface - bottom temperature effects are showh with 2 SE ranges around the estimated effects

temperature at $60 \mathrm{~m}$ around $10.3^{\circ} \mathrm{C}$. The zooplanktonthermocline depth interaction was found to be significant only for the eastern area. For increasing thermocline depths, there was an increase in herring abundance with increasing zooplankton abundances.

\section{DISCUSSION}

The results of the present study confirm the hypothesis that herring distribution is related to zooplankton biomass and to oceanographic conditions, and the utility of GAMs to analyse these relationships. The application of GAMs in the present study enabled the relationships between prespawning herring spatial distributions and oceanographic and biotic factors in summer, east and west of the Shetland-Orkney Islands (northern North Sea), to be elucidated. It was found that zooplankton biomass, sea-surface salinity and the difference between surface and bottom temperature, appear to have an effect on the herring abundance in both areas. Temperature at $60 \mathrm{~m}$ (as a main effect in the east and as an interaction with zooplankton in the west), surface temperature (as an interaction with zooplankton in both the east and the west) and thermocline depth (as an interaction effect with zooplankton in the east) also exhibited significant relationships with herring abundance. Higher than average herring 
abundance occurred in areas with a surface salinity of $35.1 \mathrm{ppt}$. This water is likely introduced into the area by the Slope Current, particularly to the west of Shetland. The east Shetland Atlantic inflow is a persistent feature of the northern North Sea during the summer and is also comprised of water of Atlantic origin (warmer, more saline) brought into the area by the Slope Current. Therefore Atlantic water is found on both sides of the Shetlands; herring prefer this water in both areas.

One possible reason for this preference for Atlantic water may be the availability of zooplankton prey in these waters. We have shown that higher zooplankton abundances tend to be associated with higher average herring abundances. Likewise, low zooplankton abundances tend to be associated with lower than average herring abundances. This can be seen as support for the previously proposed hypothesis that food supply is likely to be an important factor driving the spatial distribution of herring (Maravelias 1993, Maravelias \& Reid 1995, Maravelias et al. 1996). The present study concentrated on the small crustacean fraction of the zooplankton. During summer in the northern North Sea, small crustacean distribution is dominated by Calanus species, which represent up to $99 \%$ of the biomass. Calanus was found to form patches in areas with the higher salinities: west and north-east of the Shetlands and to be in low densities in the stratified areas (south-east of the Shetlands), presumably due to nutrient depletion. This behaviour is typical of Calanus in that area in summer ( $\mathrm{S}$. Hay pers. comm.).

Herring form schools when feeding or during periods of reproduction and migration (Parrish \& Saville 1965). Feeding schools are often associated with very productive waters, such as might be present on a particular bank (i.e. a shelf-break frontal zone) or at a boundary between 2 water masses (Laevastu 1993). This was supported by the findings of the present study: for both the east and west areas, high average herring abundance was associated with well-mixed waters and transition zones between frontal and stratified areas (surface - bottom temperature was around $2^{\circ} \mathrm{C}$ ). It has been found that the biologically productive zone associated with upwelling or mixing may be 2.5 times the width of the mixing area itself (Cushing 1971). Nutrients that are brought to the surface by turbulence as the water velocity increases over a shelf or bank can be utilized by the phytoplankton, resulting in a shelf-break front of high primary productivity. However, the highest standing stock of phytoplankton will develop over time on the more stable side of the front (Lali \& Parsons 1993). Hence, mixing results in elevated surface nutrient concentrations, high primary production, and increased numbers of zooplankton. Results of the present study are consistent with the previous hypothesis (Maravelias \& Reid 1995) that herring prefer these areas adjacent to mixing zones. We suggested that herring may select those areas for 2 reasons: firstly, due to better visibility (as herring is, mainly, a visual feeder), and secondly, due to nutrient abundance leading to the maintenance of food oases. In both areas the average herring abundance decreased with increasing difference between surface and bottom temperature values. A reasonable scenario would suggest that areas with high surface - bottom temperature values are representative of more stratified waters (i.e. difference between surface and bottom temperature is high), primary (and hence secondary) production would then be expected to be relatively poor due to nutrient depletion leading to lower food supplies.

Increased average herring abundance for deeper thermocline depths (>30 m) and for increased zooplankton abundances was in evidence for the area east of the islands. For the area west of the islands, high average herring abundances was found in cooler (i.e. temperature at $60 \mathrm{~m}$ around $10^{\circ} \mathrm{C}$ ) zooplankton-rich waters. Similar temperatures at $60 \mathrm{~m}$ were associated with high average herring abundance in the east area. In the northern North Sea ecosystem during summer, zooplankton starts its migration to deeper waters where it hibernates. In July and August the thermocline becomes well-established and Calanus finmarchicus moves deeper into cooler water beneath the thermocline (Lali \& Parsons 1993); our results are consistent with these observations.

For both east and west, areas with high zooplankton production and warmer (between 12 and $14^{\circ} \mathrm{C}$ ) and more saline (>35 ppt) surface waters were attractive to herring. The Slope Current is known to be responsible for the advection of warm, saline water into the west (directly) and east (indirectly, through the east Shetland Atlantic inflow) of the Shetlands. The present study also showed the significance of the Slope Current for the northern North Sea ecosystem through its effect in the herring-Calanus relationship. Herring prefer waters with specific salinity and temperature properties, such as are characteristic of the Slope Current. The Atlantic inflow into the North Sea is responsible for a significant input of warm, nutrientrich water into the northern North Sea, bringing in oceanic planktonic species. Well-mixed waters are attractive to herring due to the process of frontal mixing which enhances primary production, hence, phytoand zooplankton abundance.

The present work quantitatively identified the relationships between herring, Calanus, and a range of related oceanographic parameters in the northern North Sea in summer of 1995. Results indicated a high degree of coupling between herring abundance distri- 
bution and biotic and abiotic factors. Herring abundance was higher than average when:

(1) The zooplankton abundance was high.

(2) The salinity of the surface waters was around $35.1 \mathrm{ppt}$.

(3) The difference between surface and bottom temperatures was around $2^{\circ} \mathrm{C}$.

(4) The temperature at $60 \mathrm{~m}$ depth was around $10^{\circ} \mathrm{C}$.

(5) The thermocline was deeper than $30 \mathrm{~m}$ and zooplankton abundance was high.

(6) The surface temperature was between 12 and $14^{\circ} \mathrm{C}$ and zooplankton abundance was high.

Acknowledgements. This paper forms part of the first author's EC funded PhD thesis (European Commission, DG XIV, Fisheries Sector, FAIR Programme, Contract: ERB GT 96 1116]. We are grateful to Dr Gordon Swartzman, University of Washington, USA, for his guidance, valuable discussions and suggestions throughout the application of GAMs in fisheries. Part of this study was carried out while the first author was visiting the Applied Physics Laboratory, University of Washington in Seattle, USA. Financial support for that visit was provided, in part, by the Fisheries Society of the British Isles in the form of a travel grant. We also thank Steve Hay for his help in the analysis of plankton samples and useful comments regarding zooplankton distribution in the studied area. Bill Turrell provided useful insights into the oceanography of the North Sea.

\section{LITERATURE CITED}

Cushing DH (1971) Upwelling and the production of fish. Adv Mar Biol 9:334-555

Cushing DH (1989) A difference in structure between ecosystems in strongly stratified waters and in those that are only weakly stratified. J Plankton Res 11(1):1-13

Foote KG (1983) Linearity of fisheries acoustics: with additional theorems. J Acoust Soc Amer 73:1932-1940

Hamming RW (1973) Numerical methods for scientists and engineers. McGraw-Hill, New York

Hastie T, Tibshirani R (1990) Generalized additive models. Chapman and Hall, London

Hay S (1995) Egg production and secondary production of common North Sea copepods: field estimates with regional and seasonal comparisons. ICES J Mar Sci 52:315-327

Kiorboe T, Munk P, Richardson $K$, Christensen V, Paulsen $\mathrm{H}$ (1988) Plankton dynamics and larval herring growth, drift and survival in a frontal area. Mar Ecol Prog Ser 44:205-219

This article was submitted to the editor
Laevastu $T$ (1993) Marine climate, weather and fisheries. Fishing News Books, London

Lali CM. Parsons TR (1993) Biological oceanography: an introduction. Pergamon Press, Oxford

Longhurst A (1984) Heterogeneity in the ocean-implications for fisheries. Rapp PV Réun Cons Int Explor Mer 185: $268-282$

Mann KH (1993) Physical oceanography, food chains and fish stocks, a review. ICES J Mar Sci 50:105-119

Maravelias CD (1993) The relationship between herring (Clupea harengus, L.) distribution and environmental factors (salinity and temperature) in the northern North Sea. MSc thesis, University of Wales, Bangor

Maravelias CD, Reid DG (1995) Spatial relationships between herring, plankton and oceanographic conditions in the North Sea. ICES CM 1995/Q:16

Maravelias CD, Reid DG, Simmonds EJ, Haralabous J (1996) Spatial analysis and mapping of acoustic survey data in the presence of high local variability: geostatistical application to North Sea herring (Clupea harengus). Can J Fish Aquat Sci 53(7): 1497-1505

Parrish BB, Saville A (1965) The biology of the north-east Atlantic herring populations. Oceanogr Mar Biol Annu Rev 3:323-373

Raid T (1989) The influence of hydrodynamic conditions on the spatial distribution of young fish and their prey organisms. Rapp PV Réun Cons Int Explor Mer 190:166-172

Reid DG, Turrell W, Walsh M, Corten A (1997) Cross-shelf processes north of Scotland in relation to the southerly migration of western mackerel. ICES J Mar Sci (in press)

Shepherd JG, Pope JG, Cousens RD (1984) Variations in fish stocks and hypotheses concerning their links with climate. Rapp PV Réun Cons Int Explor Mer 185:255-267

Simmonds EJ (1995) Survey design and effort allocation: a synthesis of choices and decisions for an acoustic survey. North Sea herring is used as an example. ICES CM 1995/B:9

Simmonds EJ, Toresen R, Corten A, Pederson J, Reid DG, Fernandes PG, Hammer C (1996) 1995 ICES Coordinated acoustic survey of ICES divisions IVa, IVb, VIa and VIlb. ICES CM 1996/H:8

Sutcliffe WH, Drinkwater K, Muir BS (1977) Correlations of fish catch and environmental factors in the Gulf of Maine. J Fish Res Bd Can 34:19-34

Swartzman G, Huang CP, Kaluzny SP (1992) Spatial analysis of Bering Sea groundfish survey data using generalized additive models. Can J Fish Aquat Sci 49:1366-1378

Swartzman G, Silverman E, Williamson N (1995) Relating trends in walleye pollock (Theragra chalcogramma) abundance in the Bering Sea to environmental factors. Can J Fish Aquat Sci 52:369-380

Manuscript first received: September 19, 1996

Revised version accepted: January 8, 1997 